\title{
CFRTP pipe molding process using high-frequency direct resistance heating
}

\author{
K. Tanaka, J. Nakatsuka, Y. Matsuura, T. Ueda \& T. Katayama \\ Department of Biomedical Engineering, Doshisha University, Japan
}

\begin{abstract}
To deal with environmental issues, the gasoline mileage of passenger cars can be improved by reduction of the car weight. Carbon Fiber Reinforced Thermoplastics (CFRTP), which are superior in specific strength and specific modulus, is expected to be used for car body. Many pipe-shaped members have been used for structural materials for cars, and low cost and high-speed molding method for CFRTP pipe has been required. Although rapid heating process of mold has been developed by applying high-frequency direct resistance heating to the mold itself in previous studies, sufficient mechanical properties of CFRTP pipe could not be obtained because of the high viscosity of thermoplastic resin. In CFRTP molding, impregnation improvement of the resin is one of the important issues to be solved. In this study, carbon fiber thermoplastic resin preimpregnated sheet, which was impregnated with thermoplastic resin beforehand, is used as molding material to improve the quality of the CFRTP pipe. The CFRTP pipe molded with pre-impregnated sheet had less void and higher strength than the pipe molded with dry carbon and nonwoven fabric.
\end{abstract}

Keywords: CFRTP prepreg sheet, high-frequency direct resistance heating, rapid molding process.

\section{Introduction}

Within the automobile industry, in order to improve gasoline mileage and reduction of $\mathrm{CO}_{2}$ emission, light weight technology for car body is necessary to be improved $[1,2]$. Pipe-shaped parts are well used for car component parts such as suspension arm, torsion beam, door guard bar and impact beam. The reduction of weight of car by using Carbon Fiber Reinforced Thermoplastics (CFRTP) which have advantages in high specific strength and high specific modulus is 
expected $[3,4]$. Therefore, low-cost and high-speed molding method is required for CFRTP pipe molding.

Filament winding method and sheet winding method are used as the pipe molding process. Sheet winding method has an advantage that its production cycle time is shorter than that of filament winding method [5]. In previous studies, CFRTP pipe was produced by using Non-woven Stitched Multi-axial Cloth (NSMC) as semi-product material of CFRTP in sheet winding method [6]. NSMC is sheet-shaped intermediate material for CFRTP that was made by stitching carbon fibers and nonwoven matrix resin simultaneously in the process of manufacturing non-crimp stitched fabric (NCF). The composite material using $\mathrm{NCF}$ as reinforcement has less disorder in the fiber direction, and has mechanical properties superior to the composite material using textile as reinforcement [7-9]. The use of NSMC makes the lamination process simplify, and makes possible to shorten a production cycle time. For heating method of mold, high-frequency direct resistance heating of mold itself was used to reduce the production cycle time. Since this heating method does not require a coil like electromagnetic induction heating, the reduction of molding cost can be expected.

Although CFRTP pipe mold was heated rapidly by using high-frequency direct resistance heating, molded CFRTP pipe has tensile strength of $427 \mathrm{MPa}$ that was $70 \%$ of the expected value [6]. Impregnating and shaping processes were performed at the same time for the purpose of shortening the molding time. However the mechanical properties were not sufficiently obtained because of the high viscosity of the matrix resin. In CFRTP pipe molding, since a void is a cause of strength reduction, the impregnation of the resin is an important issue to be solved.

In general, in order to compensate the weak point of the high viscosity of the thermoplastic resin, in the molding of continuous fiber reinforced thermoplastics, reinforced thermoplastic laminated composites in which the resin was impregnated beforehand to reinforced fabrics are manufactured and they are formed to final products as secondary process. By separating the impregnation process and the forming process, high quality products are obtained. In this study, carbon fiber reinforced thermoplastic prepreg sheet, in which reinforcing carbon fabric was impregnated with thermoplastic resin beforehand, was manufactured and used as semi-product material for CFRTP pipe molding to improve the quality of the pipe. In addition, mechanical properties of the molded pipe were evaluated by tensile test and lateral compression test.

\section{Molding method}

\subsection{Materials for CFRTP prepreg sheet}

Non-woven Stitched Multi-axial Cloth (NSMC, Fig. 1) was used for semiproduct material of CFRTP. NSMC, in which NCF having $\left[0^{\circ} /+45^{\circ} / 90^{\circ} /-45^{\circ}\right]$ and $240 \mathrm{~g} / \mathrm{m}^{2}$ in the weight per unit area, and polyamide 6 non-woven fabric with a melting point of $211^{\circ} \mathrm{C}$, having $50 \mathrm{~g} / \mathrm{m}^{2}$ in the weight per unit area were stitched simultaneously, was used in this study. Furthermore, polyamide 6 
nonwoven fabric having $100 \mathrm{~g} / \mathrm{m}^{2}$ in the weight per unit area was put on this $\mathrm{NSMC}$ so that the volume fraction of fiber (Volume Fraction: $\mathrm{V}_{\mathrm{f}}$ ) was set for $50 \%$. Continuous carbon fiber thermoplastic prepreg sheet of $0.2 \mathrm{~mm}$ thickness was molded by a hot press molding machine under a pressure of $1.6 \mathrm{MPa}$ at $265^{\circ} \mathrm{C}$.

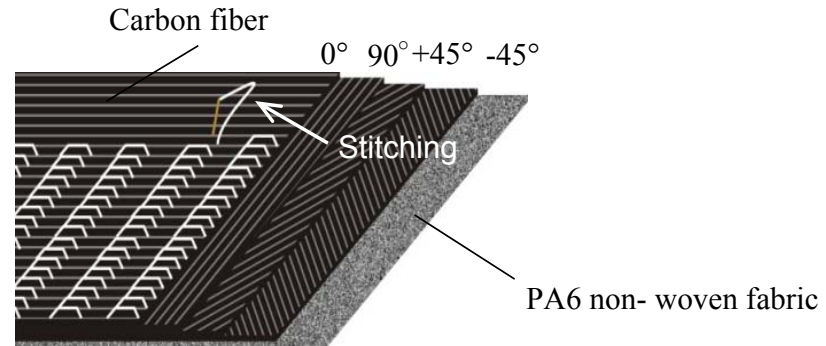

Figure 1: NSMC (Non-woven Stitched Multi-axial Cloth).

\subsection{Pipe molding procedure}

CFRTP pipe molding process is shown in Fig. 2. Carbon steel round bar made of SUS430 in the size of $300 \mathrm{~mm}$ in length and $25 \mathrm{~mm}$ in diameter was used for the inner mold. For the outer mold, carbon steel tube in the size of $50.8 \mathrm{~mm}$ in outside diameter, $2.3 \mathrm{~mm}$ in thickness, and $200 \mathrm{~mm}$ in length was used. Teflon pipe in the size of $40 \mathrm{~mm}$ in outside diameter, $7.5 \mathrm{~mm}$ in thickness, and $200 \mathrm{~mm}$ in length was covered to the inner mold. To improve the releasing property, Kapton sheet coated with a releasing agent was wound around a Teflon pipe, and CFRTP prepreg sheet of $200 \mathrm{~mm}$ in length was wound seven times on it. Kapton sheet was wound around them before covering it with the outer mold, and the outer mold was tightened by a stainless steel band.

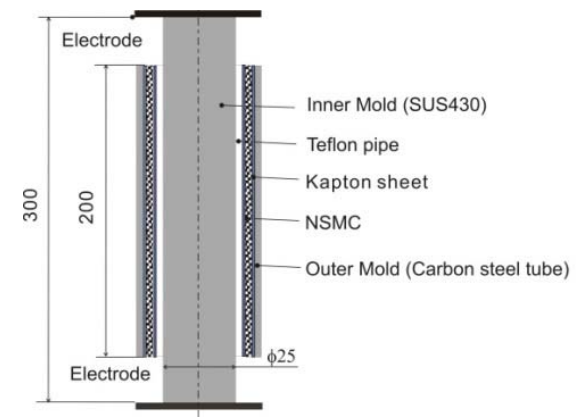

Figure 2: CFRTP pipe molding process.

The inner mold was heated by high-frequency direct resistance heating. Vacuum-tube oscillator with $30 \mathrm{~kW}$ maximum output and $185 \mathrm{kHz}$ current frequency was used as the high-frequency oscillator. After the inner mold was heated to $265^{\circ} \mathrm{C}$ at $6 \mathrm{~kW}$ power output as the molding temperature, it was held 
for one minute and air-cooled. For the production of references, NSMC and nonwoven fabric instead of prepreg sheet was used for CFRTP pipe molding as shown in the previous study [6].

\section{Tensile test for the specimens cut out from the pipe}

\subsection{Evaluation of mechanical properties}

The tensile tests were conducted by the universal testing machine (Autograph AG-100kN, Shimadzu Co., Japan), and the video non-contact extensometer (DVE-100, Shimadzu Co., Japan) was used to measure the displacement between gauge points of the specimen. The specimen, whose length and width were $170 \mathrm{~mm}$ and $10 \mathrm{~mm}$ respectively, was cut out from the molded pipe by a fine cutter. As the specimen has curvature, aluminium tab was attached to both ends of the specimen and the gap between specimen and the aluminium tab was filled with epoxy resin. The gauge length and the displacement rate were $50 \mathrm{~mm}$ and $1.0 \times 10^{-5} \mathrm{~m} / \mathrm{s}$ respectively. For evaluating the impregnation properties of a resin into fiber bundle, the section of the specimen was polished and observed with confocal microscope (Lasertec, OPTELICS H1200 M-BM).

\subsection{Results and discussions}

Fig. 3 shows the temperature history of the surface of the prepreg sheet, which was contacting to the outer mold, during pipe molding process. It was heated to the molding temperature of $265^{\circ} \mathrm{C}$ from $25^{\circ} \mathrm{C}$ in 239 seconds. Fig. 4 shows an overview of the molded CFRTP pipe. Dimensions of the pipe were $46.2 \mathrm{~mm}$ in outside diameter, $1.8 \mathrm{~mm}$ in thickness, and $180 \mathrm{~mm}$ in length. Fig. 5 shows the cross section image of the CFRTP pipe. Voids were not observed and good impregnated pipe was molded.

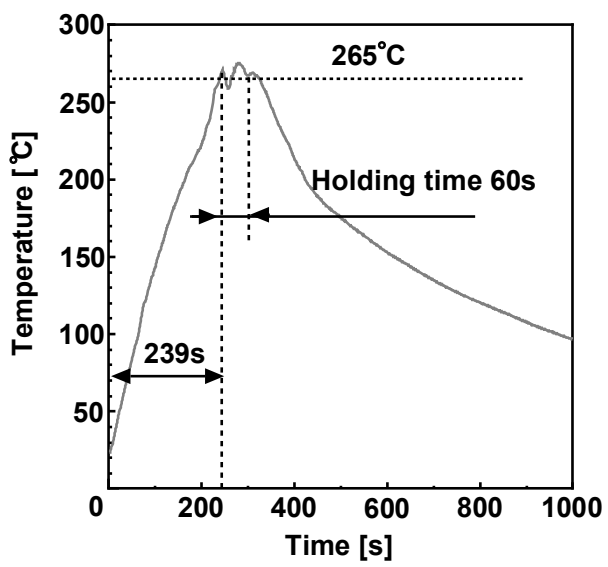

Figure 3: Temperature history of the contact surface of the prepreg sheet and the outer mold during molding process. 

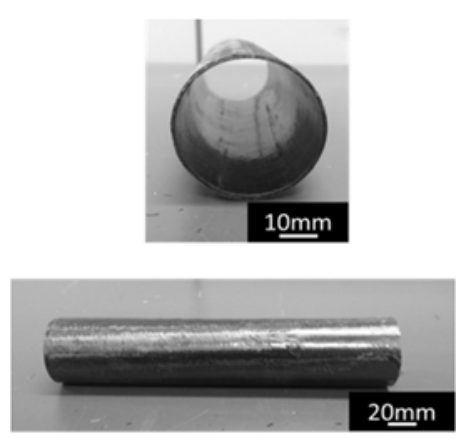

Figure 4: $\quad$ Molded CFRTP pipe.

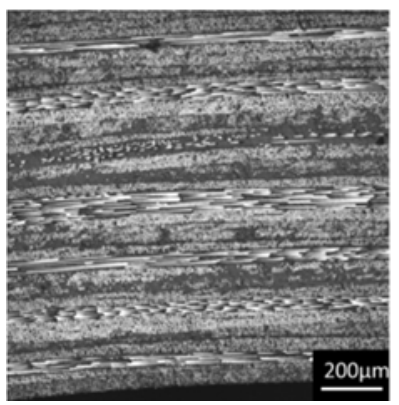

Figure 5: Cross-section image of molded CFRTP pipe.

Fig. 6 shows stress strain curve of the tensile test. Brittle behaviour was observed and the tensile strength and tensile modulus of the specimen cut out from the CFRTP pipe which was molded with prepreg sheet were $538 \mathrm{MPa}$ and $27.9 \mathrm{GPa}$ respectively. The ratio to each expected value was $95 \%$ and $89 \%$. The tensile strength and the tensile modulus of the pipe, which was directly molded with NSMC and nonwoven resin fabric, were reported to be $427 \mathrm{MPa}$ and 26.4 GPa respectively in previous study [6]. By using the prepreg sheet for pipe molding, better quality pipe can be manufactured.

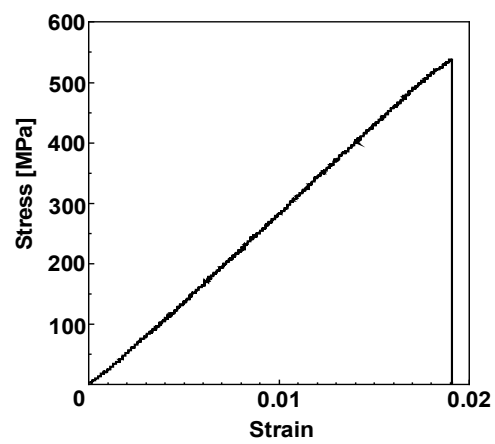

Figure 6: Stress strain curve of the specimen cut out from the CFRTP pipe. 


\section{Lateral compression test of the pipe}

\subsection{Evaluation of mechanical properties}

The lateral compression test for the molded pipe was conducted by the universal testing machine (Autograph AG-250kN, Shimadzu Co., Japan). Specimen of $50 \mathrm{~mm}$ in length was cut out from the molded pipe. The displacement of the pipe was defined as crosshead displacement, and displacement rate was set at $2.0 \mathrm{~mm} / \mathrm{min}$ based on JIS K7013. Lateral compressive strength was calculated using the next expression in reference to JIS K6911.

$$
\sigma_{f B}=\frac{3 P\left(D_{0}+D\right)^{2}}{\pi L D\left(D_{0}-D\right)^{2}}
$$

where $\sigma_{f B}$ is lateral compressive strength, $\mathrm{P}$ is maximum load, $\mathrm{L}$ is specimen length, $\mathrm{D}_{0}$ is outside diameter of the specimen, and $\mathrm{D}$ is inside diameter of the specimen.

\subsection{Results and discussion}

Fig. 7 shows lateral compressive load displacement curves of CFRTP pipes that were molded with prepreg sheet and NSMC with nonwoven resin fabric. Fig. 8 shows the compressed specimen during the lateral compression test at each displacement shown in Fig. 7. When the load reached $1903 \mathrm{~N}$, the specimen broke at the upper part, point $\mathrm{A}$ as shown in Fig. 8 (b). Then the load rose again, the specimen broke at lower part, point B as shown in Fig. 8 (c).

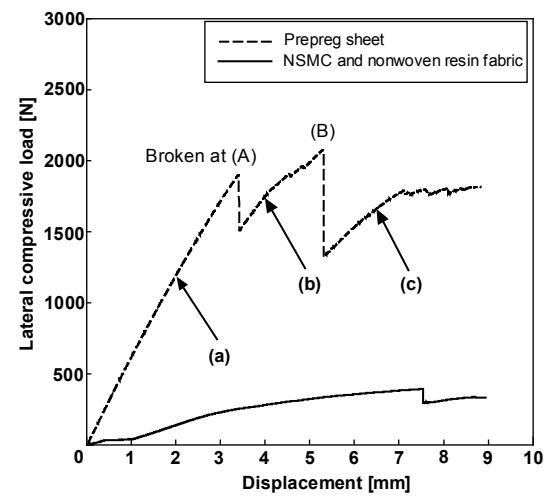

Figure 7: Lateral compressive load- displacement curve of molded pipe.

In this study, the maximum load that the specimen initially broke at point $\mathrm{A}$ was used for the expression (1) to calculate the lateral compressive strength. The lateral compressive strength of the pipe molded with prepreg sheet was $478 \mathrm{MPa}$. On the other hand, that of the pipe molded with NSMC and nonwoven resin fabric was $66 \mathrm{MPa}$. The lateral compressive strength of the pipe molded with prepreg sheet is higher than that of the pipe molded with NSMC and nonwoven resin fabric. 


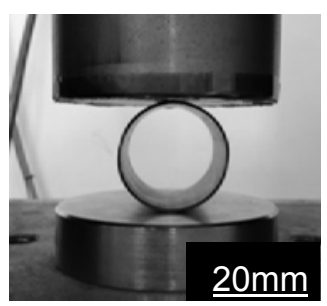

(a): Displacement $2 \mathrm{~mm}$

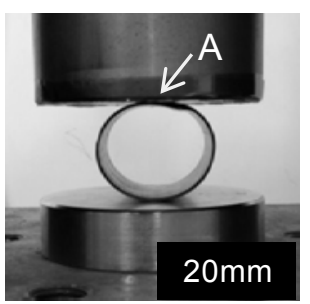

(b): Displacement $4 \mathrm{~mm}$

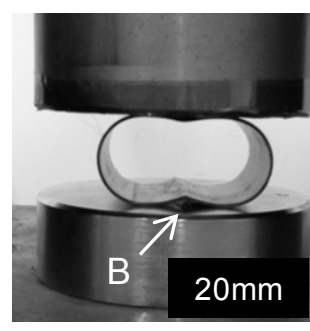

(b): Displacement $6.5 \mathrm{~mm}$

Figure 8: Compressed specimen at each displacement shown in Fig. 7.

\section{Conclusions}

Carbon fiber reinforced thermoplastic prepreg sheet, in which reinforced carbon fabric was impregnated with thermoplastic resin beforehand, was manufactured and used as semi-product material for CFRTP pipe molding. And mechanical properties of the molded pipe were evaluated by tensile test and lateral compression test. The investigation yields the following conclusions:

1. High-frequency direct resistance heating enables the heating of the mold to the molding temperature of $265^{\circ} \mathrm{C}$ from a room temperature in 239 seconds.

2. By using thermoplastic prepreg sheet, good quality CFRTP pipe, whose tensile strength, tensile modulus and lateral compressive strength were $538 \mathrm{MPa}, 27.9 \mathrm{GPa}$ and $478 \mathrm{MPa}$ respectively, can be molded.

\section{Acknowledgement}

This work was partially supported by KAKENHI (Japan Society for the Promotion of Science, Grant-in-Aid for Scientific Research (B))(26289011).

\section{References}

[1] P. Feraboli, A. Masini, L. Taraborrelli and A. Pivetti, Integrated development of CFRP structures for a topless high performance vehicle, Composite Structures.78, pp. 495-506 (2007). 
[2] F. Rezaeia, R. Yunusa, N. A. Ibrahimb and E. S. Mahdic, Development of Short-Carbon-Fiber-Reinforced Polypropylene Composite for Car Bonnet, Polymer-Plastics Technology and Engineering, Vol. 47, pp. 351-357 (2008).

[3] S.W. Beckwith, Thermoplastic composites resins matrices, Sampe Journal, Vol. 44, No. 1, pp. 70-71 (2008).

[4] R. Stewart, "New developments help composites compete", REINFORCED Plastics, Vol. 47, No. 2, pp. 27-31 (2003).

[5] F. C. Shen, "filament-wound structure technology overview", Materials Chemistry and Physics, Vol. 42, pp. 96-100, (1995).

[6] K. Tanaka, R. Harada, T. Uemura, and T. Katayama, "Development of rapid pipe moulding process for carbon fiber reinforced thermoplastics by direct resistance heating", Advanced Materials Development and Performance (AMDP2011) International Journal of Modern Physics: Conference Series, Vol. 6, pp. 616-621 (2012).

[7] K. Tanaka, N. Kohashi, Y. Kinoshita, T. Katayama and K. Uno, Compression molding of carbon fiber reinforced thermoplastics using nonwoven stitched multi-axial cloth by means of induction heating system, Journal of Society of Material Science, Vol. 58, No. 7, pp. 642-648 (2009).

[8] G. A. Bibo, P. J. Hogg and M. Kemp, "Mechanical characterisation of glass and carbon fiber reinforced composites made with non-crimp fabric", Composite science and technology, Vol. 57, pp. 1221-1241 (1997).

[9] S. V. Lomov and E. B. Belov, "Carbon composites based on multiaxial multiply stitched preforms. Part 1. Geometry of the preform", Composites Science and Manufacturing, Vol. 33, No. 9, pp. 1171-1183 (2002). 